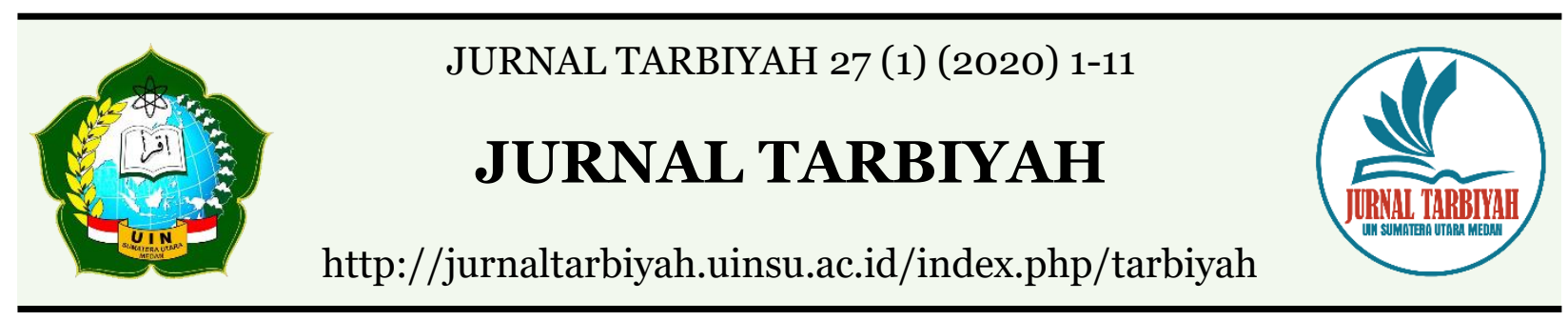

\title{
AN ANALYSIS ON TEACHERS' IDENTITY REPRESENTATIONS ON INSTAGRAM
}

\author{
Didin Nuruddin Hidayat ${ }^{1}$, Lili Samrotul Karimah², Alek³, \\ Agus Sufyan 4 \\ UIN Syarif Hidayatullah Jakarta, Indonesia

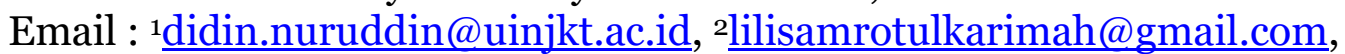 \\ 3alek@uinjkt.ac.id, 4agus.sufyan@uinjkt.ac.id
}

DOI : 10.30829/tar.v27i1.627

Accepted: March 21th, 2020. Approved: June 25th, 2020. Published: June 30th, 2020

\begin{abstract}
The teaching profession has been considered as a highly respected job in some developed countries for bringing significant impacts on the country's national growth. Therefore, teachers are generally being illustrated into some animations, videos, or pictures on websites and other internet sources. Thus, this research is aimed to investigate how teachers' identity is represented on Instagram. Ten Instagram posts related to this issue with the help of Instagram hashtag about \#teacherlife were used as the data to get the finding. The research applied the theory and method of Critical Discourse Analysis (CDA) with the perspective of multimodal discourse analysis and social semiotics. The data were analyzed by using the signing model of Saussure. Initial coding was also used to analyze the data. The finding revealed four big results, they are: the teacher's responsibility, teachers' commitment, teachers' authority, and teachers' need for recognition. Furthermore, identity is affected by some factors, where different contexts of teachers may have different identities.
\end{abstract}

Keywords: teacher, instagram, Critical Discourse Analysis, identity 


\section{INTRODUCTION}

Teaching is often being considered as an easy occupation for some people. It seems like everybody can teach. In some countries, Finland for instance, being a teacher is one of most-wanted-jobs by many people. Teacher is a well-paid profession and bring future carrier. Meanwhile, in other countries such as in American continent country, becoming a teacher is not number one choice. In September 2018, Time Magazine covered stories of teachers in USA (Reilly 2018). It has been assumed that teaching is a thankless job which teachers are underpaid within overload work. Moreover, In Indonesia, the definition of teacher is written on the article 1 Verse 1 PP RI No. 74/ 2008. It is stated that teacher is a professional educator whose responsibilities are to educate, to teach, to guide, to direct, to train, to assess, and to evaluate students in all level of education. Specifically, Law No. 14/ 2005-unit IV chapter 8-10 described a teacher as follow:

a. Teacher must academically qualified, possess teaching competence and certificate of academic qualification, competence, teacher's certificates, good in physical and intelligence, and having capacity to acknowledge national training objectives.

b. Teacher must have academic capability at any rate college degree (article 9)

c. Teacher must being competent pedagogically, personally, socially through professional education (article 10)

Based on the standards stated above, it is obvious that the teachers should prepare themself thoroughly. However, in reality, not all teachers in Indonesia are qualified with those criteria. There is a gap between the expectations with the practice. Despite all those facts, teacher, in general, is a professional job whose identity and integrity are needed to support its existence. In addition, the notion of identity has a number several concepts from various perspectives in the literature. As a result, it is hard to elaborate the term of identity concisely.

Pennington proposed one of the definitions of identity. He defined identity as the unique set of characteristics associated with a particular individual relative to the perceptions and characteristics of others (Pennington and Richards 2016). In other words, identity refers to what someone is and what make them different from each other. By the definition, it can be assumed that many factors influence the development of identity whether it comes from the person himself or from external aspects. Though there is no absolute definition of teacher identity, numerous scholars define typical thought that identity is a changing and dynamic process which is influenced by scope of external 
factors, such as life environment, and also internal factors such as feelings. In addition, identity is also influenced by individual factors.

\section{LITERATURE REVIEW}

Related with the definition of identity, the claim of good teaching application comes from the identity and integrity of the teacher seems undeniable. It is well acknowledged that teacher identity has important role in the development of teachers (Izadinia 2015). Teacher identity is characterized through teaching experiences that also defined as the concept of the professional personality (Karabay 2016). In his classic book, The Courage to Teach: Exploring the Inner Landscape of a Teacher's Life, Palmer defined "identity" and "integrity" of teacher as not only good things taht teachers act or how they overcome the problem in their career development but also refer to their weaknesses and fear in teaching environment. For that reason, building an identity for teachers is really important.

Considerable researches who were interested on teacher identity have been conducted several ways. One of the previous related research is 'Drawing identity: Beginning pre-service teachers' professional identities' (Beltman et al. 2015). In their research, Beltman et al (2015) focused on pre-service teacher's perception of teachers' identity. The participants, who were 125 pre-service teachers in an Australian university, were asked to describe themselves as the teacher they hoped to become. The researcher coded the data in the form of drawing according to the presence or absence of teachers, students and media of teaching. The result showed that pre-service teachers imagined themselves as the loving teachers who would create interesting teaching method so that they would get along with their students and become pride teachers who have good

confidence. Besides using drawing the investigation of teacher, the term of identity has also been conducted by using narratives story (Anspal, Eisenschmidt, and Löfström 2012), one-to-one interview (Khalid 2015), and teaching metaphors (Ó’Gallchóir, O’Flaherty, and Hinchion 2018).

In current digital era, everyone is able to construct their identity through many ways including on digital platform such as social media. Social media allows its users to express, discover, and even experiment their identity (Gündüz 2017). It is considered as something normal for the human experience. By this consideration, teachers can introduce themselves by building their identity through social media to make the viewer know how and when the teachers want to be recognized as a 'teacher' who has professional 
job and personal life at once, so that they can perform their task better and participate in the activities they like.

One of the popular social media platforms used by teachers or educators is Instagram. Instagram is one of smartphone applications which is designed as the photography and videography app which the users can post something in the form of picture and video within the space to write the caption related to their posts that will make the viewer impressed (Mirsarraf, Shairi, and Ahmadpanah 2017). Instagram is not only useful for schools to promote and market the institution, but also helpful for teachers to better communicate with students. Teachers should add Instagram to their social media classroom. They can use Instagram as the complement of fun assignments and school projects. Instagram also offers the possibility to create your own groups and communities as well as use hashtags to notify that community about new trending updates. This is a great way to build a loyal base of followers that will share the teachers' content with other communities of their own. In that sense, using Instagram for school can be very beneficial when it reaches target audience.

Instagram allows its users to express themselves, connect with each other, and share information through pictures and words in ways that are not reflected in the real life. Moreover, the use of Instagram's hashtag also enables the users to express their identity on discussing one topic. There are number of teachers and educators benefit this idea of Instagram to reflect on their teaching life or personal life. Trough Instagram, they celebrate their profession by sharing inspiration, creative ideas for the classroom, funny facts from teachers' daily routine, motivational quotes, and useful stuff to survive the school year. Their Instagram content affects their virtual identity and respectively influence how people see them.

Moreover, Instagram gives people a way to share their lives with friends and family through pictures. The application is easy to use by simply taking mobile snapshots and storing them digitally. The concept of this popular social networking site is based on the passion for photographs. Instagram's membership is extensive and it offers a significantly higher percentage of brand engagement in comparison to other social media sites. In addition, another attractive feature is the ability to share Instagram posts on other social networks. Thus, Instagram is an important social media platform for business exposure and growth. Instagram users interact frequently with brands and the site brings more engagement with followers. Here are the other functions of Instagram: picture sharing, story update, messaging platform and group messaging. 
Regarding to the illustration above, it is interesting to study teachers' identity represented on Instagram. Digital representation of teachers can give new insight to see teachers' identity from other perspective. Moreover, as Instagram consist of video, picture, caption text, and hashtag so it is considered as a medium of multimodal content generation and publication, so that social semiotic framework is applied to this kind of social media. Therefore, the social semiotic aspects of this application are investigated. Based on those research backgrounds, the researcher is going to investigate how teacher's identity is represented on Instagram.

\section{METHOD}

This research has been qualitatively conducted by using the theory and method of Critical Discourse Analysis (CDA) with the perspective of multimodal discourse analysis and social semiotics. In social semiotics, the investigation of discoure that consist of multiple modalities (such as images, sound, and music) with linguistic and textual content is examined through multimodal discourse analysis (O'Halloran et al. 2011). The term of semiotics was defined by Saussure, a founder of the field, as "the study of the life of signs within social life" (Macey 2000). Since Instagram has a multimodal content, this approach is appropriate to be used in this research.

Furthermore, several hashtags related to the issue was used to get the data, such as: \#teacherslife and \#teacherslifestyle. Ten Instagram posts that have relevant topic about teacher were analyzed. The researchers took the most recent posts and excluded the post with audio and video in order to minimize the chance the issue of the reliability of the data. After getting the data, the researcher analyzed the Instagram posts by using the sign model of Saussure. The researchers then code the data into several themes. The analysis process was started by considering the images used as the analogy of the content. Besides, the textual component was also analyzed to investigate how the concepts referenced and the language used demonstrates the teachers' identities. The analysis also considers why these particular images or texts have come to represent teachers' feeling and what can be inferred from the association of these particular images with the post themes regarding the teachers' identity. 


\section{FINDING AND DISCUSSION}

As stated previously, this research was aimed to investigate how teachers' identity is represented on Instagram. Based on the analysis, four aspects of teacher identity representation emerged. The result will be elaborated point by point below.

1. Responsibility as a teacher

Based on the data analysis, some pictures conveyed that teachers have so many responsibilities. In the illustration of normal person (non-teacher) brain with teacher's brain, the teachers are described to have so many things in their mind. It is not like what they imagine that become a teacher is not only dealing with good students but they're also responsible with various kind of students. Several ideas of teachers' identities are against the teachers' expectation. Consequently, it can lead to the reinterpretation of the meaning that enable and change identities. Their teaching competency is highly needed to do their responsibility. In fact, it has been mentioned that competency in teaching included pedagogical aspects. The way the teachers create the activities in their lessons, how they manage their classes and how far they have mastered the subject are the aspects that show their teaching competency. Moreover, teaching is also dealing with more abundant and more complicated works such as administration stuff and parenting.

In this matter, the aspects of teachers' professional identity are covered. The categories in this finding are also suitable with the literature stated, that teachers' identities cover how they recognize themselves in terms of their profession, their personal objectives and how they treat themselves in relation to others. Sharing the technique and method of teaching among teachers seemed to be one way to engage to the development of teachers' identities.

\section{Commitment as a teacher}

Becoming a teacher means people have to commit with everything related to the teacher responsibilities, such as the time that will be spent and the effort will be made to run this job. Some pictures of the teachers even describe that their tasks are not ended while they are in school. They sometimes have to bring home the school tasks.

Moreover, not only have so many responsibilities, teachers also have to deal with planning and time management. Based on the data analysis, teacher identity can be observed from whether the teachers commit with their planning and time management. Some teachers are resolving their task in a tight deadline. This matter really examined their commitment as teachers. In this situation, there is also possibility to the rejection of 
teachers' identity. Teachers tend to ask themselves whether being a teacher is a right choice for them or not. For instance, in one picture of an old woman sitting and seems being resentful by thinking that tomorrow is Monday. Or, there is a picture of Sympson sits on bed at 4 a.m as the metaphore of how teacher wakes up every Monday morning and think if they should confess that they are sick to avoid school is a description that sometimes teacher discarded their identity. All in all, keep up the commitment is a must to remain being a professional teacher.

\section{Authority as a teacher}

Previously, teachers were assumed to have the largest authority in the class. However, form the analysis teachers are struggling with their authorities. Students challenged their teachers' authority far more nowadays than they did in the past. Moreover, teachers do not only have to deal with students but also other stakeholders in their institutions. Teachers frequently work under- pressure with the authority of school management, school principal and even students' parents.

To fulfill their role identity as the teachers at school, teachers place themselves as a role model for students. The teachers tried their best in order to make the students keep on the right track. To be able to act the role, assistances of parents are also important. However, parents sometimes see school differently. Some parents assume that they can peacefully entrust their children at school and give all the responsibility to the teachers. Sometimes, when something bad happened to their children they can just easily blame the teachers. And the worst, the school also puts all the responsibility to the teachers. In this case, teachers' identities are at risk. Many cases showed that parent has an uneasy authority over the teachers. They sometimes lost their respect for teachers.

\section{Recognition as a teacher}

It is obvious that the need of recognition also important in shaping teacher's identity. In the data analysis, the life of a teachers is described with a picture of many people queuing for giving complaints to teachers, while not even one coming for compliments. It may seem exaggerating, but it is what teachers feel in the reality.

As illustrated in one picture, there is a cat looking sad and tired, as the metaphor of how teachers feel when they already have overworked and under-appreciated meanwhile when they get their salary bills were not comparable. From the data analysis, the issue of teachers are so underpaid are clearly declared. The need of recognition will lead to teachers' motivation. What trigger someone to end up being a teacher and stay in the 
educating is defined as teaching motivation. In addition, colleagues, working hours, and financial states are other variables that influence teachers' motivation.

Hence, here are some of the ways in which the use of application such as Instagram is able to bring benefits the educational process:

a. Instagram \& Spatial Intelligence

Spatial intelligence is a mental process through the brain attempts to interpret certain types of incoming information. This information is basically based on visual - pictures, maps, plans, and others. This kind of intelligence is used very effectively in Instagram exercises. The mind judges the distance, size and other aspects of an object before clicking pictures or viewing them, and also when editing pictures.

b. Instagram \& Linguistic Intelligence

Linguistic intelligence is all about honing students' language skills. When a user uploads pictures, his or her friends and followers can view the pictures. Likewise, teachers can upload pictures and share then to their students and ask them to make observations or provide specific types of feedback. This encourages students to use their language skills.

c. Instragram \& Logical Mathematical Intelligence

Logical Mathematical Intelligence is basically detection of patterns, and the ability to evaluate problems and think logically. This intelligence can be used when teachers share some pictures to the students and ask them to work on them - like cropping an image or improving its look by using Photoshop application. Likewise, there is an interesting exercise to be applied to the students, such as cropping a picture into various pieces and creating a puzzle out of it.

d. Instagram \& Interpersonal Intelligence

The ability of a person to comprehend desires, motivation and the intentions of others is referred as Interpersonal intelligence. Teachers can engage the students in Instagram group activities like "all about my classmate" to exercise this intelligence.

e. Usage of Instagram and iPhoneography in Art \& Photography Classes The IphonePhotographySchool application helps people take better pictures with the iPhone. By understanding the camera settings and other ways to improve on picture quality can really help students to be prepared to focus on creating marvelous pictures. 


\section{f. Instagram \& Intrapersonal Intelligence}

The ability to understand other people and appreciate someone's fears, feelings and motivations is defined as Interpersonal Intelligence. This intelligence is addressed through the act of allowing students to work independently and reflect on some of the pictures they capture and create.

\section{CONCLUSION}

Teachers build their identity in various ways. Though there is no an absolute definition of teacher identity, numerous scholars defined a typical thought that identity is a changing and dynamic process which is influenced by scope of outer encounters such as beneficial encounters and interior encounters (for example: feelings and individual components). In addition, teachers' identity is the consequence of the dynamic exchange with other related individual or network. The encouraging identity is then the aftereffect of a connection between teachers' personal life and the community through the cultural and institutional condition. There are some functions of Instagram such as: picture sharing, story update, messaging platform and group messaging.

Teacher identities that being represented on Instagram give us another insight of teachers' identity. Based on the research finding, many ideas of teachers' identity are against the teachers' expectation. As the result, it lead to the reinterpretation of the meaning that enable and change identities. The finding of this research revealed four big aspects, they are; teacher's responsibility, teachers' commitment, teachers' authority, and teachers' need of recognition. Furthermore, as explained above, identity is affected by many factors, hence different context of teachers may have different identity. What missing from this research is that it didn't focused on where this situation happened. There should be more specific reasons why certain thing happens in different places. Therefore, the future research is required to discuss deeply about teacher's identity from specific context and situation. Moreover, this research is focused only on general issue of teachers' identity. Some other issues such as teacher's appearance and school environment are not discussed in this research.

\section{REFERENCES}

Anspal, Tiina, Eve Eisenschmidt, and Erika Löfström. 2012. "Finding Myself as a Teacher: Exploring the Shaping of Teacher Identities through Student Teachers' Narratives."
Teachers
and
Teaching
18
(2):
197-216. 
https://doi.org/https://doi.org/10.1080/13540602.2012.632268.

Beltman, Susan, Christine Glass, Judith Dinham, Beryl Chalkand, and Bich Nguyen. 2015. "Drawing Identity: Beginning Pre-Service Teachers' Professional Identities." Issues in Educational Research 25 (3): 225-45.

Gündüz, Ugur. 2017. "The Effect of Social Media on Identity Construction." Mediterranean Journal of Social Sciences 8 (5): 85-92. https://doi.org/https://doi.org/10.1515/mjss-2017-0026.

Izadinia, Mahsa. 2015. "A Closer Look at the Role of Mentor Teachers in Shaping PreService Teachers' Professional Identity.” Teaching and Teacher Education 52: 1-10.

Karabay, Aysegul. 2016. "An Investigation of Prospective Teachers' Views Regarding Teacher Identity via Metaphors.” Eurasian Journal of Educational Research 16 (55): 1-35. https://doi.org/https://doi.org/10.14689/ejer.2016.65.01.

Khalid, Fariza. 2015. "The Dimensions of Identities and Its Roles in Shaping Teachers' Effectiveness." Mediterranean Journal of Social Sciences 6 (3): 306-14. https://doi.org/https://doi.org/10.5901/mjss.2015.v6n3s1p306.

Macey, David. 2000. The Penguin Dictionary of Critical Theory. New York: Penguin.

Mirsarraf, Mohammadreza, Hamidreza Shairi, and Abotorab Ahmadpanah. 2017. "Social Semiotic Aspects of Instagram Social Network.” In 2017 IEEE International Conference on Innovations in Intelligent Systems and Applications (INISTA), 460465. Gdynia: IEEE.

Ó'Gallchóir, Ciaran, Joanne O’Flaherty, and Carmel Hinchion. 2018. "Identity Development: What I Notice about Myself as a Teacher.” European Journal of $\begin{array}{llll}\text { Teacher } & \text { Education } & 41 & \text { (2): }\end{array}$ https://doi.org/https://doi.org/10.1080/02619768.2017.1416087.

O’Halloran, Kay, Sabine Tan, Bradley Smith, and Alexey Podlasov. 2011. "Multimodal 
Didin Nuruddin Hidayat, et al / JURNAL TARBIYAH 27 (1) (2020) 1-11

Analysis within an Interactive Software Environment: Critical Discourse Perspectives." Critical Discourse Studies 8 (2): 109-25.

Pennington, Martha C., and Jack C. Richards. 2016. "Teacher Identity in Language Teaching: Integrating Personal, Contextual, and Professional Factors." RELC Journal 47 (1): 5-23. https://doi.org/https://doi.org/10.1177/o033688216631219.

Reilly, Katie. 2018. “'I Work 3 Jobs And Donate Blood Plasma to Pay the Bills.' This Is What It's Like to Be a Teacher in America," September 13, 2018. http://time.com/longform/teaching-in-america/. 